\title{
Should flavours be banned in cigarettes and e-cigarettes? Evidence on adult smokers and recent quitters from a discrete choice experiment
}

\author{
John Buckell, ${ }^{1}$ Joachim Marti, ${ }^{2}$ Jody L Sindelar ${ }^{1}$
}

\begin{abstract}
- Additional material is published online only. To view, please visit the journal online (http://dx.doi.org/10.1136/
\end{abstract} tobaccocontrol-2017-054165).

${ }^{1}$ School of Public Health, Yale University, New Haven, Connecticut, USA

${ }^{2}$ Institute of Social and Preventive Medicine (IUMSP), CHUV, Université de Lausanne, Lausanne, Switzerland

\section{Correspondence to} Dr John Buckell, School of Public Health, Yale University, New Haven, CT 06520, USA; john.buckell@yale.edu

Received 20 November 2017 Revised 18 April 2018 Accepted 19 April 2018 Published Online First 28 May 2018
Check for updates

To cite: Buckell J, Marti J, Sindelar JL. Tob Control 2019:28:168-175.

\begin{abstract}
Objectives To provide the policy-relevant estimates of impacts of alternative flavour bans on preferences and demand for cigarettes and e-cigarettes in adult smokers and recent quitters.
\end{abstract}

Methods A best-best discrete choice experiment (DCE) is used to elicit smokers' and recent quitters' preferences for flavours, price, health impact and nicotine level in cigarettes and e-cigarettes. Choice of tobacco products and an opt-out option were examined. An efficient design yielded 36 choice sets. Exploded logit choice models were estimated. Flavour bans are modelled by restricting flavour coefficients in the estimated model. Setting and participants A sample of 2031 adult smokers and recent quitters was recruited to complete an online survey and DCE.

Results Current smokers and recent quitters, on average, prefer cigarettes and menthol cigarettes over flavoured e-cigarettes. However, there is substantial preference heterogeneity by younger adults (ages 18-25), race/ethnicity and respondents with higher education. Our predictions suggest that a ban on menthol cigarettes would produce the greatest reduction in the choice of cigarettes $(-5.2 \%)$, but with an accompanying increase in e-cigarettes use (3.8\%). In contrast, banning flavours in e-cigarettes, while allowing menthol in cigarettes would result in the greatest increase in the selection of cigarettes $(8.3 \%)$, and a decline in the use of e-cigarettes (-11.1\%). A ban on all flavours, but tobacco in both products would increase 'opting-out' the most (5.2\%) but would also increase choice of cigarettes $(2.7 \%)$ and decrease choice of e-cigarettes (-7.9\%).

Conclusions $\mathrm{A}$ ban on flavoured e-cigarettes alone would likely increase the choice of cigarettes in smokers, arguably the more harmful way of obtaining nicotine, whereas a ban on menthol cigarettes alone would likely be more effective in reducing the choice of cigarettes. A ban on all flavours in both products would likely reduce the smoking/vaping rates, but the use of cigarettes would be higher than in the status quo. Policy-makers should use these results to guide the choice of flavour bans in light of their stance on the potential health impacts both products.

\section{INTRODUCTION}

Currently in the USA, e-cigarettes are available in over 7000 flavours, ${ }^{1}$ but all characterising flavours except menthol are banned in cigarettes. E-cigarettes are increasingly popular in the USA, but are largely unregulated. This is in contrast to cigarettes, which have become less popular over time, but are highly regulated by the US government. Although e-cigarettes are considered to be less harmful than cigarettes, there are concerns that they may lead to initiation of e-cigarettes, in particular by those who had not used nicotine products in the past. ${ }^{2}$ The introduction of e-cigarettes has led to use of multiple products estimated to be $38.8 \%$ of adult tobacco users. Among those, $23 \%$ are dual cigarettes/e-cigarettes users, the most common combination. ${ }^{3}$ Research shows that almost three-quarters of young adults initiating e-cigarettes use a flavoured product. ${ }^{4}$

This growth in e-cigarettes use has led to concern over their impact on the health of the public and interest in regulating them. Some cities and counties have already implemented bans on the sale of flavoured cigarettes and e-cigarettes. At the national level, the Center for Tobacco Products of the Food and Drug Administration (FDA) is considering banning flavours in tobacco products. ${ }^{5}$ However, flavour regulation is complicated due to the potential substitutability or complementarity of products as a function of flavours as well as varying views on the extent to which e-cigarettes are less harmful than cigarettes. ${ }^{6-9}$ Flavours appeal to some consumers. ${ }^{10-12}$ That there are stark differences in the availability of flavours across products complicates predictions about the potential impacts of alternative flavours bans on public health. With the exception of Kenkel et al, ${ }^{13}$ who found limited switching due to a flavour ban in e-cigarettes, empirical evidence is lacking on e-cigarettes. Studies examining menthol cigarette bans ${ }^{14-19}$ found evidence of a reduction in smoking in the long run, ${ }^{16}$ while Kotlyar et al ${ }^{17}$ found that African-American smokers would likely switch to non-menthol products instead of quitting. Other studies found that banning flavours in cigarettes reduced adolescent cigarette use ${ }^{18}$; one study found a reduction of youth and young adults' self-reported use of both cigarettes and e-cigarettes if all flavours were banned in all tobacco products. ${ }^{19}$

In this study, we provide the policy-relevant predictions of the impact of flavour bans on the choice of cigarettes and e-cigarettes. Specifically, we estimate the impact on product choices of a set flavour bans that could be implemented by the FDA. We use an online discrete choice experiment (DCE) on 2031 US smokers (ie, smoked at least 100 cigarettes in their lifetime) and recent quitters (ie, quit smoking in the last 12 months) ages 18-64; the sampling was matched to a national smoking survey. We estimate preferences for flavours in cigarettes and e-cigarettes while controlling for other 
attributes of both products, and study how these preferences vary with individual characteristics. We then predict the demand for cigarettes and e-cigarettes under alternative policies banning flavours and discuss which flavour policy bans would be optimal under alternative criteria for protecting public health.

In contrast to most of the literature on flavour bans, we examine their impact on both cigarettes and e-cigarettes. That is, we focus on how product-specific flavours and their bans affect the complementarity and substitutability of choices across products. We also add to the tobacco literature that uses experimental approaches to examine substitutability across tobacco products. ${ }^{2021}$ For example, previous studies used auction-based experiments online, ${ }^{22}$ in the field ${ }^{212324}$ or in person, ${ }^{2526}$ and purchasing tasks online. ${ }^{27} 28$ They find evidence of a significant substitutability as a function of price, ${ }^{28}$ as a function of the frequency of use of similar products ${ }^{22}$ and the level of nicotine. ${ }^{23}$ Several papers have used their online experimental tobacco marketplace to study substitutability 22 and have found substitutability between cigarettes and e-cigarettes as price varies.

In sum, our DCE approach allows us to predict the impact of alternative policies that are not currently in place and to focus on substitutability driven by flavour bans. In addition, our large, up to date, data set of current and former smokers, matched to a national survey, allows us to estimate the heterogeneity in impact of these bans across smoking status and individual characteristics.

\section{METHODS}

A DCE is a survey-based experimental approach aimed at eliciting individual preferences for goods and services. ${ }^{30}$ In a DCE, respondents make a series of choices across products described using a set of attributes and levels. The relative importance of each attribute and the value of alternative options can be derived from the choices, using choice models. The approach has been extensively applied in health policy and public health research, ${ }^{31}$ in tobacco research, ${ }^{32}$ and e-cigarettes. ${ }^{33-35} \mathrm{~A}$ strength of DCE is that it allows examination of the likely impact of alternative policies that are not currently in place.

In this study, we aim to estimate the causal effect of flavours and other attributes on the choice of cigarettes and e-cigarettes, and then to predict the impact of flavoured cigarette ban alternatives. ${ }^{30}$ In this DCE, respondents choose their preferred option from a set of four products described by four attributes: flavour, health impact, amount of nicotine and price. See table 1 , figure 1.

In this best-best DCE ${ }^{36}$ respondents were asked to respond to scenarios by choosing their two favourite options among cigarettes, e-cigarettes and 'none of these' ('none' hereafter). Note that the 'none' option appears two times to allow respondents to opt-out of both their first and second choice. Because the choice options are specific products, this is a 'labelled' experiment, which is beneficial for realism. ${ }^{37}$ We used a D-efficient survey design which generated 36 different choice sets. ${ }^{38}$ To reduce response burden, respondents were randomised to 1 of 3 blocks of 12 choices, each had different sets of scenarios seen in a different order. Kruskal-Wallis tests indicated the randomisation was applied correctly.

The specific flavours were chosen to reflect currently available flavoured products in the USA: tobacco and menthol for cigarettes; and tobacco, menthol, fruit and sweet for e-cigarettes. The overwhelming majority of the many e-cigarette flavours can be classified as menthol, fruit or sweet. ${ }^{1139} 40$ Note that tobacco is the underlying flavour for all cigarettes but must be added to e-cigarettes. In the paper, when we refer to flavours, we are referring to all but tobacco.
Table 1 Experimental design: attributes and levels that were varied throughout the choice scenarios

\begin{tabular}{lll}
\hline & E-cigarette & Combustible cigarette \\
\hline Flavour & Plain tobacco & Plain tobacco \\
\hline & Menthol & Menthol \\
& Fruit & \\
& Sweet & \\
\hline Life years lost by average user & 10 & 10 \\
& 5 & \\
& 2 & \\
\hline & Unknown & \\
Level of nicotine & High & High \\
\hline & Medium & Medium \\
& Low & Low \\
\hline Price & None & \\
& US\$4.99 & US\$4.99 \\
& US\$7.99 & US\$7.99 \\
& US\$10.99 & US\$10.99 \\
& US\$13.99 & US\$13.99 \\
\hline
\end{tabular}

Health risk was expressed as years of life lost by an average user. For cigarettes, this was 10 to reflect the known harm. ${ }^{41}$ For e-cigarettes, the four levels are: 2, 5, 10 and unknown; these reflected the likely lower health risk of e-cigarettes and the uncertainty surrounding true health effects. ${ }^{42}$ The levels of nicotine were low, medium and high for both products. A level of 'none' was provided for e-cigarettes as nicotine-free options are available. We did not use quantitative levels of nicotine (eg, in $\mathrm{mg}$ ) as this was confusing to respondents. The qualitative levels used convey sufficient, ordered information. Finally, we defined

\begin{tabular}{|c|c|}
\hline Option 1: Tobacco Cigarette & Option 2: Tobacco Cigarette \\
\hline $\begin{array}{l}\cdot \text { Flavor: Tobacco } \\
\quad \text { Nifilir } \quad \text { Nicotine level: High } \\
\cdot \text { Die earlier: } 10 \text { Years } \\
\cdot \text { Price: } \$ 4.99\end{array}$ & $\begin{array}{l}\text { - Flavor: Tobacco } \\
\text { - Nicotine level: High } \\
\text { - Die earlier: } 10 \text { years } \\
\text { - Price: } \$ 13.99\end{array}$ \\
\hline Option 3: E-cigarette & Option 4: E-cigarette \\
\hline $\begin{array}{l}\text { - Flavor: Fruit } \\
\cdot \text { Nicotine level: High } \\
\cdot \text { Die earlier: } 2 \text { Years } \\
\cdot \text { Price: } \$ 13.99\end{array}$ & $\begin{array}{l}\cdot \text { Flavor: Sweet } \\
\cdot \text { Nicotine level: High } \\
\cdot \text { Die earlier: Unknown } \\
\cdot \text { Price: } \$ 4.99\end{array}$ \\
\hline
\end{tabular}

First preference

Second preference

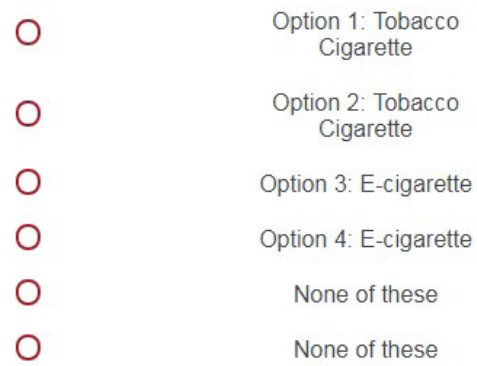

Figure 1 Example choice scenario. 
price as the price paid for 20 cigarettes or the equivalent volume of e-cigarettes (using a conversion ratio of 1 disposable cigarette/1 e-cigarette refill to 30 cigarettes. ${ }^{43}$ We used this to make the prices of cigarettes realistic and the comparisons meaningful. Levels are based on market prices. ${ }^{44}$ The prices are displayed in table 1. Note the design accounts for the imbalance in the definition of attributes. ${ }^{45}$ A survey was administered to collect socioeconomic data and smoking behaviour information on each respondent.

We took steps to increase the quality of the choice data collected. Prior to the DCE, detailed narrative and visual information describing the products (cigarettes or e-cigarettes) and their features were provided (see online supplementary appendix D for details). A sample experiment task was provided giving respondents practice in responding. We also used 'forced responses' to prevent respondents from skipping through the survey. And we used a minimum time threshold to remove respondents who rushed through. Finally, we used attention filters embedded in the survey to check that respondents were paying attention (eg, 'select option 2 to show that you are paying attention').

\section{Participants}

We recruited a sample of 2031 adult smokers and recent quitters online using the survey firm Qualtrics. To be eligible, current smokers and recent quitters had to have smoked at least 100 cigarettes in their lifetime and had to be US residents between ages 18 and 64. Our sample size is large relative to other choice experiments in health, and it is in excess of minimum sample size calculations. ${ }^{46}$ Respondents were matched to proportions of smokers in regional/demographic quotas using data from the 2014 Behavioral Risk Factor Surveillance System based on six regions, gender and age bands. Details are provided in online supplementary appendix A.

\section{Analysis}

We used exploded multinomial logit (MNL) models to analyse respondents' choices. Each of the 2031 individuals made 2 choices in 12 choice scenarios. Thus, there were 48744 choices from 24372 observations. We specified our initial model to be a function of product-specific terms and attributes. To align our model with the FDA's policy options, we impose two features on the model. First, we combined fruit and sweet flavours into a single group as they are commonly considered jointly. ${ }^{34}{ }^{35}$ Second, by interacting the 'product constant terms' with each of the flavours we were able to examine the productflavour pairings directly. We referred to these combinations as 'flavoured product constant terms'. Use of both of these improved the fit of the model. We are primarily interested in the estimates of the flavoured product constant terms: menthol cigarette, tobacco e-cigarette, menthol e-cigarette and fruit/sweet e-cigarette. Each of these constants represents the preference for each flavoured product relative to a tobacco cigarette (the reference case) at the sample level. See online supplementary appendix B for the model specification.

We then interacted these flavoured product constant terms with sociodemographic variables that were collected in the survey. This allowed us to estimate heterogeneity by smoking status and socioeconomic and demographic characteristics, which increases the realism of our predictions. Attributes were dummy coded with the exception of price which was treated as a continuous variable. We believe that dummy coding is a better approach compared with effects coding as the interpretation of the reference category is clearer. ${ }^{47}$ We used the resulting model to make the predictions of the impacts of the set of policies. All analyses were conducted using Nlogit (V.6.0).

\section{Policy predictions}

The estimated choice models were used to predict what percentage of the sample chose each product type and the option of none. Using the estimated utilities from the choice model, we estimated the probability that each product would be chosen by each individual in each choice scenario. ${ }^{48}$ These are called choice probabilities and they sum to 1 across all options, in each choice scenario. The sample-average choice probability for each product is the model's prediction of how many individuals will choose that product. These are called choice shares which are estimated using our models. When making our predictions, we model regulation alternatives by restricting flavours and recalculating the choice shares. The differences between the base and the revised choice shares across policy options are the model's prediction of the FDA policies.

We first predicted choices under the status quo and then imposed the set of policy scenarios (table 2) to predict the smoking choices under the alternative bans. Alternative 1 reflects a comprehensive ban on all flavours. Alternative 2 reflects a policy where only menthol would be allowed for both products. The other scenarios reflect a ban on menthol cigarettes only (alternative 3), often considered as a policy option; a ban on menthol in both cigarettes and e-cigarettes (alternative 4 ) as is the case in Canada and a flavour ban specific to e-cigarettes with a status quo for cigarettes (alternative 5). For instance, to analyse a ban on all e-cigarette flavours but not on tobacco ('alternative 5 ' in table 2), we set the coefficients on flavours in e-cigarettes to 0 and use the estimated model to obtain revised choice probabilities, which yield shifts in choices. These shifts reveal the potential impact of each policy.

Table 2 Potential flavour bans policy options*

\begin{tabular}{|c|c|c|c|c|}
\hline \multirow[b]{3}{*}{ Policy } & \multicolumn{4}{|c|}{ Flavours by product } \\
\hline & \multicolumn{2}{|c|}{ Cigarettes (cig) } & \multicolumn{2}{|c|}{ E-cigarettes (e-cig) } \\
\hline & Menthol & Fruit/sweet & Menthol & Fruit/sweet \\
\hline Alternative 1: ban all flavours & Ban & Ban & Ban & Ban \\
\hline Alternative 2: only allow menthol e-cig & Ban & Ban & Allow & Ban \\
\hline Alternative 3: ban all cig flavours & Ban & Ban & Allow & Allow \\
\hline Alternative 5 : ban all e-cig flavours & Allow & Ban & Ban & Ban \\
\hline
\end{tabular}

*We focus on menthol and sweet/fruit bans as cigarettes are tobacco flavoured and as the policy focus has been primarily on these flavours. 
Table 3 Flavoured product choice models

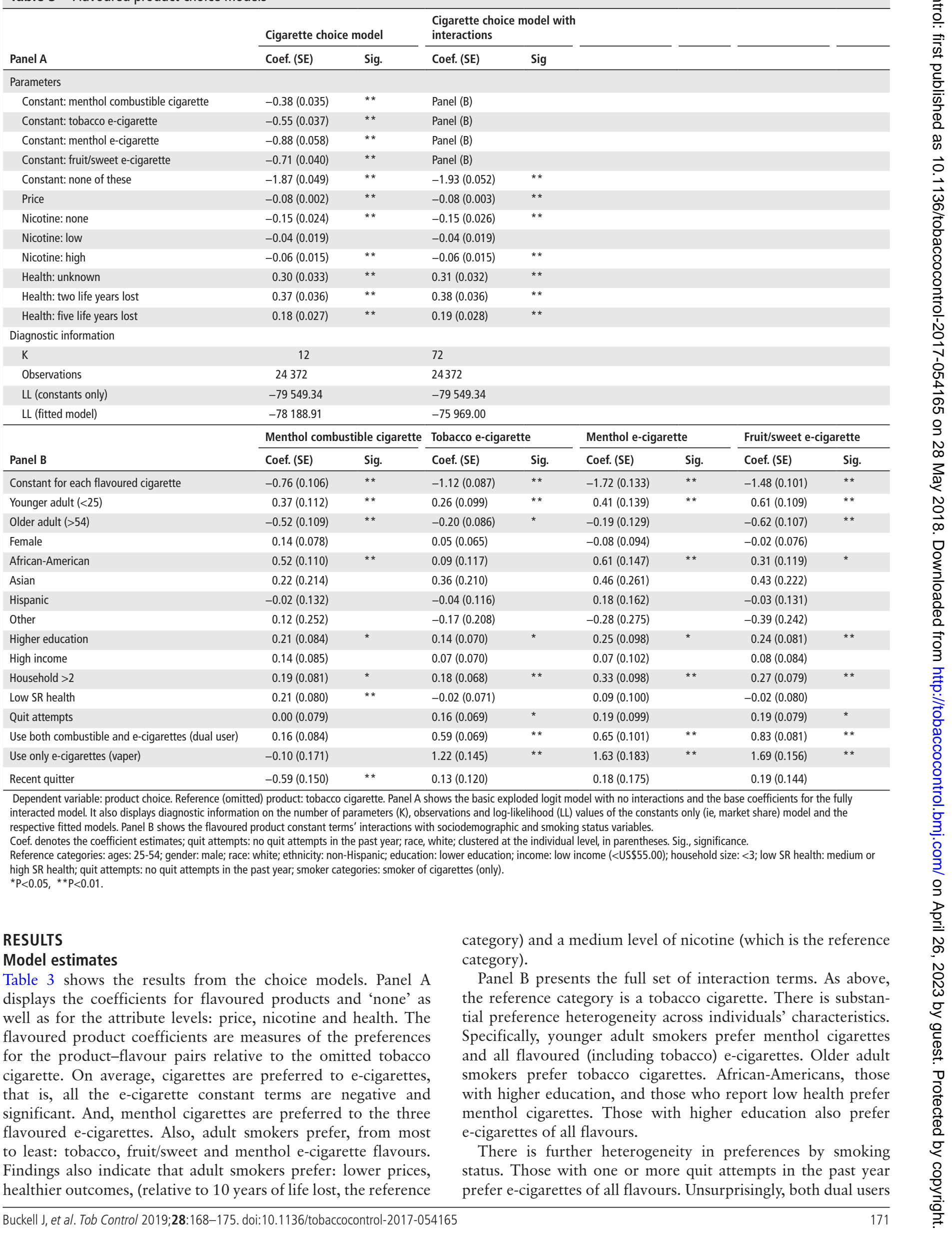


Table 4 Policy predictions of product choice shares and percentage changes in product choice shares across alternative flavours

\begin{tabular}{|c|c|c|c|c|c|c|c|c|c|c|}
\hline \multirow[b]{4}{*}{ Policy } & \multicolumn{4}{|l|}{ Panel A } & \multicolumn{3}{|l|}{ Panel B } & \multicolumn{3}{|l|}{ Panel C } \\
\hline & \multicolumn{4}{|c|}{ Permitted flavours by product } & & & & & & \\
\hline & \multicolumn{2}{|c|}{ Combustible cigarettes } & \multicolumn{2}{|c|}{ E-cigarettes } & \multicolumn{3}{|c|}{ Product choice shares $(\%)$} & \multicolumn{3}{|c|}{ Change in choice shares (\%) } \\
\hline & Menthol & Fruit/sweet & Menthol & Fruit/sweet & $\begin{array}{l}\text { Combustible } \\
\text { cigarette }\end{array}$ & E-cigarette & None of these & $\begin{array}{l}\text { Combustible } \\
\text { cigarette }\end{array}$ & E-cigarette & None of these \\
\hline Current US policy & Allowed & Banned & Allowed & Allowed & 45.2 & 37.5 & 17.2 & $\mathrm{~N} / \mathrm{a}$ & $\mathrm{N} / \mathrm{a}$ & $\mathrm{N} / \mathrm{a}$ \\
\hline Alternative $1^{*}$ & Ban & Ban & Ban & Ban & 47.9 & 29.6 & 22.4 & 2.7 & -7.9 & 5.2 \\
\hline Alternative 2 & Allow & Ban & Allow & Ban & 45.8 & 32.8 & 21.4 & 0.6 & -4.7 & 4.2 \\
\hline Alternative $3 \dagger$ & Ban & Ban & Allow & Allow & 40.0 & 41.3 & 18.8 & -5.2 & 3.8 & 1.6 \\
\hline Alternative 4 & Ban & Ban & Ban & Allow & 41.7 & 38.8 & 19.4 & -3.5 & 1.3 & 2.2 \\
\hline Alternative 5 & Allow & Ban & Ban & Ban & 53.5 & 26.4 & 20.2 & 8.3 & -11.1 & 3 \\
\hline
\end{tabular}

Each row corresponds to a policy scenario; these are defined also in table 1. Panel A, 'permitted flavours by product', shows the availability of menthol and fruit/sweet flavours for cigarettes and e-cigarettes: 'Allowed' or 'Allow' shows when the flavour is permitted, 'Banned' or 'Ban' shows when the flavour is banned. Panel B, 'product choice shares', shows the percentage of predicted choices for each product. Panel C, 'change in choice shares', shows the percentage change in predicted choices from the current US policy to the policy scenario, which is the difference between the current policy and the predicted policy share(s). See methods for calculation of the choice shares.

*Denotes the policy with the largest increase in the 'none of these' option. There may be error from rounding in the estimates.

tDenotes the policy with the largest predicted reduction in cigarette choice.

and vapers (those using only e-cigarettes) show very strong preferences for all e-cigarettes. Further, vapers prefer e-cigarettes to cigarettes. Specifically, the coefficient for the interactions of vaper and tobacco e-cigarette is positive and greater in absolute magnitude than the negative constant term for tobacco e-cigarettes. Thus, all else equal, vapers prefer tobacco e-cigarettes to tobacco cigarettes (though insignificantly). Also, vapers prefer fruit/sweet e-cigarettes to tobacco cigarettes, but not to menthol e-cigarettes. Last, recent quitters have a strong aversion to menthol cigarettes.

\section{Testing and robustness}

A number of formal tests are applied to assess the sensitivity of the results. Broadly, these include: tests of the model structure by comparing the reported estimates to those obtained from a mixed logit (that relaxes the independence of irrelevant alternative assumption ${ }^{48}$ of the MNL); tests of the utility function specification and validity checks. In all cases, test results support the findings in the tables. As an informal validity test, we note that our findings are similar to those in the literature: young adults prefer non-tobacco flavours ${ }^{34-36} 49-52$ and older adults prefer tobacco flavour ${ }^{193639}$; African-Americans' prefer menthol ${ }^{52-54}$; those with higher education prefer e-cigarettes ${ }^{49} 51$ and quit attempters and dual users prefer e-cigarettes. ${ }^{44-57}$ Details are presented in online supplementary appendix C.

\section{Policy predictions}

Table 4 displays the predicted choice shares across the set of flavour bans for sample averages. Each panel displays the following: Panel A repeats the description of the set of bans from table 2; Panel B provides the predictions of the impact of bans on choice shares and Panel $\mathrm{C}$ provides the percentage changes in the choice shares comparing the current policy to each of the alternative bans (calculated from Panel B). Each row relates to one of the potential policies described. As seen in the first row of Panel $\mathrm{B}$ of table 4, the predicted choice shares under the set of current flavour bans are: $45.2 \%$ for cigarettes, $37.5 \%$ for e-cigarettes and $17.2 \%$ for 'none.' This compares to $51 \%$ of cigarettes-only users, $31 \%$ of dual users and $7 \%$ of e-cigarettes-only users in our sample (see online supplementary appendix A), suggesting that a portion of the predicted share of e-cigarettes reflects dual users' preferences.
Results show that policy-makers seeking to minimise the use of cigarettes should ban only menthol in cigarettes (policy alternative 3 ). This results in the lowest choice of cigarettes which, at $40.0 \%$, represents a $5.2 \%$ reduction in the percentage of cigarette choices (Panel C). Of this reduction, the majority goes to e-cigarettes at $3.8 \%$, with the remaining going to 'none' at $1.6 \%$.

Under alternative 1 , the use of both products is minimised leading to the highest choice of 'none' at $22.4 \%$. In this case, e-cigarette choice declines by $7.9 \%$ and instead, people increase their choice of cigarettes by $2.7 \%$ and 'none' by $5.2 \%$. See in Panel C.

Importantly, a ban on all e-cigarette flavours but tobacco is an inferior option for either of the above goals, as alternative 5 indicates. Although this comprehensive ban would result in the largest reduction in selecting either product, selection of cigarettes would increase from $45.2 \%$ to $53.5 \%$. Unfortunately, $8.3 \%$ would change from e-cigarettes to cigarettes and only around 3.0\% would change from e-cigarette to 'none.' Thus, this policy would likely drive current e-cigarette users towards vaping or smoking more than towards abstinence. However, as above, part of the change from e-cigarettes to cigarettes might be more people becoming dual users instead of an increase in cigarettes-only use.

\section{DISCUSSION}

\section{Findings and policy implications}

These results indicate that flavours of cigarettes and e-cigarettes drive choices across products and opting-out (ie, selecting neither). Consequently, flavour bans drive the choice of product. These findings are derived from a DCE that generates the choice data used to estimate preferences which are in turn used to make the predictions. Results from the choice models indicate the following on average for our sample. Adult smokers and recent quitters prefer cigarettes to e-cigarettes, which is in keeping with national smoking statistics. ${ }^{3}$ Further, they tend to prefer tobacco to sweet, fruit and menthol flavours. However, there is substantial heterogeneity in flavour preferences, with some individuals preferring flavours. These results, including the estimated heterogeneity, are used to predict the impact of alternative bans. The patterns of preferences that we found are also found in the wider literature. ${ }^{11} 1334405859$ 
Policy-makers can use these predictions to inform the selection of optimal flavour bans based on their policy goals. Such goals will likely depend on the policy-makers' view of the relative impact on health of both products. We posit two likely goals, to: (1) minimise the selection of cigarettes, arguably the most harmful to health and (2) maximise the choice of abstaining, which we proxy with the opt-out option (ie, 'none'). Our predictions suggest that banning all flavours in e-cigarettes except tobacco, while allowing menthol in cigarettes, would result in the greatest increase in the selection of cigarettes but a decline in the use of e-cigarettes. By comparison, a ban only on menthol cigarettes would produce the greatest reduction in the use of cigarettes, and much of this movement from cigarettes would be to e-cigarettes with a smaller percentage opting-out (ie, selecting 'none'). Thus, it is likely that a menthol ban on cigarettes would most improve public health given that cigarettes impose the most significant harms. A ban on non-tobacco flavours in both products would increase the choice of opting-out ('none') the most but would also increase the use of cigarettes and reduce the choice of e-cigarettes by a relatively large amount. These predictions highlight the importance of simultaneously considering the impact of flavour bans in both cigarette types on cigarettes, e-cigarettes and choosing none of the products. Our results add to the quite limited literature on FDA flavour bans predictions. ${ }^{13}$

\section{Strengths and limitations}

A key strength of this study is that it makes needed, policy-relevant, predictions about a set of potential flavour bans. We are the only study that we know of that examines alternative bans in the USA in both cigarettes and e-cigarettes and the impact of these on the choice of both products and opting-out ('none'). Further, we use the DCE approach which is one of the few approaches that allows for rigorous and quantitative examination of the set of counterfactual flavour ban policies in advance of setting such policies. Also, we collected a large, and national data set of current and former adult smokers which was matched to a national survey. Our models allow for rich heterogeneity in preferences which adds precision to our predictions. In addition, we have conducted our experiment in line with best practices ${ }^{60}$ and have applied a broad range of robustness checks and sensitivity analyses that support our findings. Combining these, we are thus able to make realistic quantitative estimates of the impact of alternative flavours bans across both cigarettes and e-cigarettes for the USA.

Despite the above strengths, our study has several limitations. First, there is a risk of hypothetical bias in all DCEs, ${ }^{61}$ but we help address this by analysing current and recent smokers who frequently make such real-world decisions. ${ }^{62}{ }^{63}$ Other studies have shown comparability between experimental and real-world behaviours for tobacco. ${ }^{64}{ }^{65}$ Second, the meaning of the 'none' option is somewhat ambiguous. While it may reflect a willingness to quit smoking in a given scenario, it may also reflect that the respondent would not choose any of the given options but might use other products. Third, the study does not examine the use of other tobacco products, such as pipe tobacco or hookah. Fourth, we do not observe whether smokers alter their consumption quantity depending on the product selected; for example, in changing to e-cigarettes, smokers may decide to smoke more or less heavily. Fifth, we use generic products instead of brands in the choice sets. The use of brands might have made the tasks more realistic, although using a specific brand can in itself introduce bias. Sixth, our efficient design mitigated attribute imbalance, but did not necessarily fully balance the attributes because of restrictions we imposed; we prioritised the realism of the choice scenarios over the balance of the design to uphold the quality of the data. Last, youth smoking decisions should be examined separately, but is beyond the scope of this study. However, with 36.5 million adult smokers in the USA, our results are critical for informing policy.

\section{CONCLUSIONS}

The predictions of this study are timely, given that the FDA has been actively considering flavour bans in tobacco products. ${ }^{5}$ Interest by the FDA is part of a broader movement towards adopting flavour bans; bans on sales of flavoured tobacco products have been imposed at county and municipal levels within the USA, and bans on menthol cigarettes have been announced or implemented by the European Union, Canada and other countries. ${ }^{66} 67$

Our results have important policy implications for selection of flavour bans in the USA. We conclude that flavour bans can be effective levers to affect smokers' choices. Alternative flavour bans can either enhance the protection of the health of the public or worsen it, by driving smokers to alternative products or to obtaining. ${ }^{68-70}$ These results have some perhaps surprising implications that could prove valuable to lawmakers and regulators in crafting the best policies for public health.

\section{What this paper adds}

- Menthol cigarettes are appealing to some smokers; and flavours are a key aspect of the appeal of e-cigarettes.

- Banning menthol in cigarettes is likely to reduce smoking rates. Banning characterizsing flavours in cigarettes has reduced adolescent smoking; banning characteriszing flavours in e-cigarettes has limited impact on adult smokers' cigarette and e-cigarette choices.

- Almost $40 \%$ of smokers are dual or poly users. Evidence suggests smokers may substitute between tobacco products following relative price changes. However, with one exception, the substitutability between product types following alternative flavour bans has not been investigated in the literature.

- We study preferences of current adult smokers and recent quitters for flavours in cigarettes and e-cigarettes and make predictions on the use of both products for a range of alternative flavour bans.

- Our results indicate possible substitution between cigarettes and e-cigarettes as flavour availability varies.

- Our findings suggest that banning menthol in cigarettes while allowing flavours in e-cigarettes is likely to produce the greatest reduction in cigarettes smoking. However, banning flavours in both product types is likely to have the greatest reduction on overall use of cigarettes and e-cigarettes.

Acknowledgements We used the survey firm Qualtrics for data collection. We thank Catherine Maclean for contributions to the design of the experiment. We thank Kurt Petschke, Yale School of Public Health, for his additional assistance.

Contributors JB: conducted the analyses, contributed to the drafting of the manuscript. JM and JLS: contributed to the drafting of the manuscript, advised on the data analyses. All authors: designed the survey, designed the experiment, interpreted the findings, reviewed and approved the final version of the manuscript.

Funding Research reported in this publication was supported by grant number P50DA036151 from the National Institute on Drug Abuse (NIDA) and FDA Center for Tobacco Products (CTP). 
Disclaimer The content is solely the responsibility of the author(s) and does not necessarily represent the official views of the National Institutes of Health or the Food and Drug Administration.

Competing interests None declared.

Patient consent Not required.

Ethics approval Yale University Human Subjects Committee.

Provenance and peer review Not commissioned; externally peer reviewed.

(c) Article author(s) (or their employer(s) unless otherwise stated in the text of the article) 2019. All rights reserved. No commercial use is permitted unless otherwise expressly granted.

\section{REFERENCES}

1 Zhu SH, Sun JY, Bonnevie E, et al. Four hundred and sixty brands of e-cigarettes and counting: implications for product regulation. Tob Control 2014;23(suppl 3):iii3-9.

2 Barrington-Trimis JL, Samet JM, McConnell R, et al. Flavorings in electronic cigarettes: an unrecognized respiratory health hazard? JAMA 2014;312:2493-4.

3 Anon. Tobacco-product use by adults and youths in the United States in 2013 and 2014. N Engl J Med 2018;378:342-53.

4 Harrell MB, Weaver SR, Loukas A, et al. Flavored e-cigarette use: characterizing youth, young adult, and adult users. Prev Med Rep 2017;5:33-40.

5 Food and Drug Administration. FDA announces comprehensive regulatory plan to shift trajectory of tobacco-related disease, death. Maryland, USA: Food and Drug Administration, 2017

6 Kenkel DS. Healthy innovation: vaping, smoking, and public policy. J Policy Anal Manage 2016;35:473-9.

7 Ribisl KM, Seidenberg AB, Orlan EN. Recommendations for U.S. Public policies regulating electronic cigarettes. J Policy Anal Manage 2016;35:479-89.

8 Royal College of Physicians. Nicotine without smoke: tobacco harm reduction. London: Royal College of Physicians, 2016.

9 NHS Health Scotland. Consensus statement on e-cigarettes. Edinburgh: NHS Health Scotland, 2017.

10 Berg CJ, Barr DB, Stratton E, et al. Attitudes toward e-cigarettes, reasons for initiating e-cigarette use, and changes in smoking behavior after initiation: a pilot longitudinal study of regular cigarette smokers. Open J Prev Med 2014;4:789-800.

11 Berg CJ. Preferred flavors and reasons for e-cigarette use and discontinued use among never, current, and former smokers. Int J Public Health 2016;61:225-36.

12 Patel D, Davis KC, Cox S, et al. Reasons for current E-cigarette use among U.S. adults. Prev Med 2016;93:14-20.

13 Kenkel D, Peng S, Pesko M, et al. Mostly harmless regulation? Electronic cigarettes, public policy and consumer welfare. Cambridge, MA: National Bureau of Economic Research, 2017

14 O'Connor RJ, Bansal-Travers M, Carter LP, et al. What would menthol smokers do if menthol in cigarettes were banned? Behavioral intentions and simulated demand. Addiction 2012;107:1330-8.

15 D'Silva J, Amato MS, Boyle RG. Quitting and switching: menthol smokers' responses to a menthol ban. Tob Regul Sci 2015;1:54-60.

16 Levy DT, Pearson JL, Villanti AC, et al. Modeling the future effects of a menthol ban on smoking prevalence and smoking-attributable deaths in the United States. Am J Public Health 2011;101:1236-40.

17 Kotlyar M, Mills AM, Shanley R, et al. Smoker response to a simulated ban of mentho cigarettes: a pilot study. Tob Regul Sci 2015;1:236-42.

18 Courtemanche CJ, Palmer MK, Pesko MF. Influence of the flavored cigarette ban on adolescent tobacco use. Am J Prev Med 2017;52:e139-46.

19 Harrell MB, Loukas A, Jackson CD, et al. Flavored tobacco product use among youth and young adults: what if flavors didn't exist? Tob Regul Sci 2017;3:168-73.

20 Pearson JL, Richardson A, Niaura RS, et al. e-cigarette awareness, use, and harm perceptions in US adults. Am J Public Health 2012;102:1758-66.

21 Bickel W, Moody L, Snider S, et al. The behavioral economics of tobacco products. In: Hanoch Y, Barnes A, Rice T, eds. Behavioral economics and healthy behaviors: key concepts and current research. New York: Routledge, 2018.

22 Rousu MC, Beach RH, Corrigan JR. The effects of selling complements and substitutes on consumer willingness to pay: evidence from a laboratory experiment. Canadian Journal of Agricultural Economics/Revue canadienne d'agroeconomie 2008;56:179-94.

23 Quisenberry AJ, Koffarnus MN, Hatz LE, et al. The experimental tobacco marketplace i: substitutability as a function of the price of conventional cigarettes. Nicotine Tob Res 2016;18:1642-8.

24 Monchuk DC, Rousu MC, Shogren JF, et al. Decomposing the value of cigarettes using experimental auctions. Nicotine Tob Res 2007:9:93-9.

25 Rousu M, Nonnemaker J, Farrelly M. The value of countermarketing information to smokers: evidence from field auctions. Journal of Agricultural and Applied Economics 2011;43:607-20.

26 Rousu MC, O'Connor RJ, Thrasher JF, et al. The impact of product information and trials on demand for smokeless tobacco and cigarettes: evidence from experimental auctions. Prev Med 2014;60:3-9.
27 Thrasher JF, Rousu MC, Hammond D, et al. Estimating the impact of pictorial health warnings and "plain" cigarette packaging: evidence from experimental auctions among adult smokers in the United States. Health Policy 2011;102:41-8.

28 O'Connor RJ, June KM, Bansal-Travers M, et al. Estimating demand for alternatives to cigarettes with online purchase tasks. Am J Health Behav 2014;38:103-13.

29 Snider SE, Cummings KM, Bickel WK. Behavioral economic substitution between conventional cigarettes and e-cigarettes differs as a function of the frequency of e-cigarette use. Drug Alcohol Depend 2017;177:14-22.

30 Louviere JJ, Hensher D, Swait J. Stated choice methods and applications. New York: Cambridge University Press, 2000.

31 de Bekker-Grob EW, Ryan M, Gerard K. Discrete choice experiments in health economics: a review of the literature. Health Econ 2012;21:145-72.

32 Regmi K, Kaphle D, Timilsina S, et al. Application of discrete-choice experiment methods in tobacco control: a systematic review. Pharmacoecon Open 2018;2:1-13.

33 Pesko MF, Kenkel DS, Wang $\mathrm{H}$, et al. The effect of potential electronic nicotine delivery system regulations on nicotine product selection. Addiction 2016;111:734-44.

34 Shang C, Huang J, Chaloupka FJ, et al. The impact of flavour, device type and warning messages on youth preferences for electronic nicotine delivery systems: evidence from an online discrete choice experiment. Tob Control 2017:tobaccocontrol-2017-053754.

35 Czoli CD, Goniewicz M, Islam T, et al. Consumer preferences for electronic cigarettes: results from a discrete choice experiment. Tob Control 2016;25(e1):e30-6.

36 Ghijben $P$, Lancsar E, Zavarsek S. Preferences for oral anticoagulants in atrial fibrillation: a best-best discrete choice experiment. Pharmacoeconomics 2014;32:1115-27.

37 de Bekker-Grob EW, Hol L, Donkers B, et al. Labeled versus unlabeled discrete choice experiments in health economics: an application to colorectal cancer screening. Value Health 2010;13:315-23.

38 Hensher D, Rose JM, Greene W. Applied choice analysis. Second edn. Cambridge: Cambridge University Press, 2015.

39 Bonhomme MG, Holder-Hayes E, Ambrose BK, et al. Flavoured non-cigarette tobacco product use among US adults: 2013-2014. Tob Control 2016;25(Suppl 2):ii4-13.

40 Pepper JK, Ribisl KM, Brewer NT. Adolescents' interest in trying flavoured e-cigarettes. Tob Control 2016;25(Suppl 2):ii62-ii66.

41 Jha P, Ramasundarahettige C, Landsman V, et al. 21st-century hazards of smoking and benefits of cessation in the United States. N Engl J Med 2013;368:341-50.

42 Dinakar C, O'Connor GT. The health effects of electronic cigarettes. N Engl J Med 2016:375:1372-81.

43 Cuomo RE, Miner A, Mackey TK. Pricing and sales tax collection policies for e-cigarette starter kits and disposable products sold online. Drug Alcohol Rev 2015;35:110-4.

44 Marti J, Buckell J, Maclean JC, et al. To 'Vape' or Smoke? A discrete choice experiment among U.S. adult smokers. National Bureau of Economic Research Working Paper Series 2016:No. 22079.

45 Bliemer M, Collins A. Experimental design and choice experiments. In: Hensher D, Greene W, Rose JM, eds. Applied choice analysis. Cambridge: Cambridge University Press, 2015.

46 de Bekker-Grob EW, Donkers B, Jonker MF, et al. Sample size requirements for discrete-choice experiments in healthcare: a practical guide. Patient 2015;8:373-84.

47 Daly A, Dekker T, Hess S. Dummy coding vs effects coding for categorical variables: Clarifications and extensions. Journal of Choice Modelling 2016;21:36-41.

48 Train K. Discrete choice methods with simulation. Cambridge: Cambridge University Press, 2009.

49 Carrieri V, Jones AM. Smoking for the poor and vaping for the rich? Distributional concerns for novel nicotine delivery systems. Econ Lett 2016;149:71-4.

50 Huang LL, Baker HM, Meernik C, et al. Impact of non-menthol flavours in tobacco products on perceptions and use among youth, young adults and adults: a systematic review. Tob Control 2017:26:709-19.

51 Hartwell G, Thomas S, Egan M, et al. E-cigarettes and equity: a systematic review of differences in awareness and use between sociodemographic groups. Tob Control 2017;26.

52 Villanti AC, Johnson AL, Ambrose BK, et al. Flavored tobacco product use in youth and adults: findings from the first wave of the PATH study (2013-2014). Am J Prev Med 2017:53:139-51.

53 Rock VJ, Davis SP, Thorne SL, et al. Menthol cigarette use among racial and ethnic groups in the United States, 2004-2008. Nicotine Tob Res 2010;12(Suppl 2):S117-24.

54 Giovino GA, Villanti AC, Mowery PD, et al. Differential trends in cigarette smoking in the USA: is menthol slowing progress? Tob Control 2015;24:28-37.

55 Beard E, West R, Michie $S$, et al. Association between electronic cigarette use and changes in quit attempts, success of quit attempts, use of smoking cessation pharmacotherapy, and use of stop smoking services in England: time series analysis of population trends. BMJ 2016;354:i4645.

56 Hartmann-Boyce J, McRobbie H, Bullen C, et al. Electronic cigarettes for smoking cessation. Cochrane Database Syst Rev 2016;9:CD010216.

57 Zhu SH, Zhuang YL, Wong S, et al. E-cigarette use and associated changes in population smoking cessation: evidence from US current population surveys. BMJ 2017;358:j3262 
58 Office of the Surgeon General. Preventing tobacco use among youth and young adults: a report of the surgeon general. Washington, DC: US Department of Health and Human Services, 2012.

59 Tobacco Products Scientific Advisory Committee (TPSAC). Menthol cigarettes and public health: review of the scientific evidence and recommendations. Rockville, MD: Food and Drug Administration, 2011.

60 Reed Johnson F, Lancsar E, Marshall D, et al. Constructing experimental designs for discrete-choice experiments: report of the ISPOR Conjoint Analysis Experimental Design Good Research Practices Task Force. Value Health 2013;16:3-13.

61 Harrison G. Real choices and hypothetical choices. In: Hess S, Daly A, eds. Handbook of Choice Modelling. Cheltenham: Edwards Elgar Publishing, 2014.

62 McFadden D. The new science of pleasure: consumer choice behavior and the measurement of well-being. In: Hess S, Daly A, eds. Handbook of choice modelling. Cheltenham: Edward Elgar, 2014.

63 McFadden D. Stated preference methods and their applicability to environmental use and non-use valuations. In: McFadden D, Train K, eds. Contingent valuation of environmental goods: a comprehensive critique. Cheltenham: Edward Elgar, 2017.
64 Few LR, Acker J, Murphy C, et al. Temporal stability of a cigarette purchase task. Nicotine Tob Res 2012;14:761-5.

65 Wilson AG, Franck CT, Koffarnus MN, et al. Behavioral economics of cigarette purchase tasks: within-subject comparison of real, potentially real, and hypothetical cigarettes. Nicotine Tob Res 2016;18:524-30.

66 Public Health Law Center. U.S. sales restrictions on flavored tobacco products (2017). St Paul, USA: Public Health Law Center, 2017.

67 Public Health Law Center. How other countries regulate flavored tobacco products (2015). St Paul, USA: Public Health Law Center, 2015.

68 Goniewicz ML, Gawron M, Smith DM, et al. Exposure to nicotine and selected toxicants in cigarette smokers who switched to electronic cigarettes: a longitudinal within-subjects observational study. Nicotine Tob Res 2017;19:160-7.

69 Shahab L, Goniewicz ML, Blount BC, et al. Nicotine, carcinogen, and toxin exposure in long-term e-cigarette and nicotine replacement therapy users: a cross-sectional study. Ann Intern Med 2017;166:390-400.

70 National Academies of Sciences, Engineering, and Medicine. Public health consequences of e-cigarettes. Washington, DC: The National Academies Press, 2018. 